\title{
MANIFESTAÇÕES PATOLÓGICAS CONSTATADAS EM COBERTURAS DE PRÉDIOS PÚBLICOS DA CIDADE DE TERESINA OBJETO DE INSPEÇÕES PELO TCE/PI
}

\author{
ALMEIDA, FRANCISCO \\ Assisente de Controle Externo \\ Tribunal de Contas do Estado do Piauí \\ Piauí; Brasil \\ rogeanio.almeida@tce.pi.gov.br \\ MACHADO NETO, RAIMUNDO \\ Auditor de Controle Externo \\ Tribunal de Contas do Estado do Piauí \\ Piauí; Brasil \\ raimundo.machado@tce.pi.gov.br
}

\author{
LIMA, JOÃO \\ Acadêmico de Engenharia Civil \\ Universidade Federal do Piauí \\ Piauí; Brasil \\ joaovr107@hotmail.com
}

\author{
SANTANA, CLAUDENY \\ Assistente de Controle Externo \\ Tribunal de Contas do Estado do Piauí \\ Piauí; Brasil \\ claudeny.santana@tce.pi.gov.br
}

\section{RESUMO}

O presente trabalho trata de estudo acerca de manifestações patológicas em prédios públicos de Teresina/PI, especificamente em coberturas de edificações hospitalares da rede pública municipal. Tomando por base inspeções realizadas por equipe técnica do TCE/PI, procedeu-se à análise das prováveis causas, propondo-se, oportunamente, possíveis soluções mitigadoras para as manifestações encontradas, sobretudo no que se refere aos serviços de manutenção predial nas áreas cobertas. No âmbito das obras públicas, objeto do presente trabalho, verificou-se haver repetição dessas ocorrências, haja vista que, para a realidade local, as contratações geralmente são realizadas a partir de projetos básicos deficientes, apresentando falhas como detalhamento construtivo inexequível ou insuficiente, especificações de materiais inadequados e incompatibilidade entre projetos, acarretando, por consequência, técnicas construtivas ineficientes com o agravamento das patologias identificadas.

Palavras-chave: manifestações patológicas, obras públicas, coberturas.

\section{ABSTRACT}

The present work aims to study pathological manifestations in public buildings in Teresina/PI, specifically in hospital roofs from the municipal public system of health. Taking as basis inspections made by a technical team from TCE/PI, there was the analysis of the probable causes, proposing possible solutions for the manifestations found, mainly about building maintenance in covered areas. In the scope of public work, matter of the present study, it was found that there is repetition of these occurrences, which is due to the fact that, for the local reality, the basic projects usually come to public bidding with failures such as unworkable or insufficient constructive detailing, inappropriate materials specification and incompatibility between projects. Resulting in inefficient constructive techniques with the aggravation of the identified pathologies.

Keywords: pathological manifestations, public work, roofs.

\section{INTRODUÇÃO}

Conforme Gomide, Fagundes Neto e Gullo (2009), Patologia da Edificação consiste no estudo que cuida da natureza e das modicações das condições físicas ou funcionais, produzidas por falhas de construção ou anomalias construtivas, através de auditorias, perícias ou ensaios técnicos. Isso inclui, também, as fases de planejamento, projeto e execução, além de ações que visam evitar defeitos em tais fases, iniciando desde a concepção da edificação, a fim de prevenir as anomalias construtivas, bem como minimizar falhas de manutenção durante a fase de uso da edificação.

De acordo com Saldanha (2012), as falhas de construção constituem-se de vícios de manutenção, passando pelas fases de plano, procedimentos e operação. Essas falhas se classificam como: de Planejamento, quando são oriundas do programa de manutenção; de Execução, quando se originam dos procedimentos e insumos adotados; Operacionais, quando provenientes dos registros e controles técnicos e de Gestão, quando causadas por desvios de qualidade e custos. 
Já as anomalias construtivas são vícios construtivos, advindos tanto da concepção do projeto, especificação dos materiais quanto da execução da edificação. Estas classificam-se como: endógenas, quando esses vícios ocorrem por causa do projeto, dos materiais ou da execução; exógenas, quando os danos são causados por fatores externos à edificação; naturais, quando os danos advém de fenômenos da natureza e funcionais, quando os danos são provenientes da degradação ocasionada pelo uso ou pelo término da vida útil dos elementos constituintes (SALDANHA, 2012).

Conforme a NBR - Norma Brasileira 15575-1 (ABNT - Associação Brasileira de Normas Técnicas, 2013), desempenho é o comportamento em uso de uma edificação e de seus sistemas durante sua respectiva vida útil. Sendo a vida útil o período de tempo em que um edifício e seus respectivos sistemas constituintes servem para as atividades aos quais foram projetados, considerando a peridiocidade e a correta execução dos processos de manuntenção estabelecidos. Portanto, a manutenção tem como consequências inerentes o aumento da vida útil e a melhora do desempenho ao longo da mesma, conforme apresentado na Figura 1.

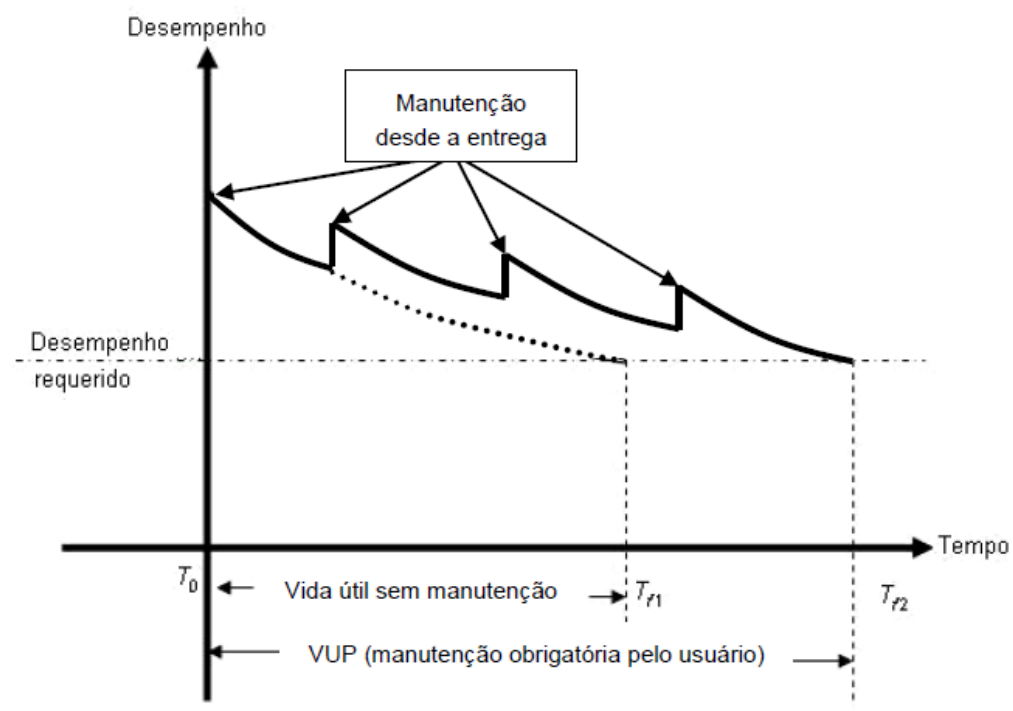

Figura 1: Desempenho ao longo do tempo Fonte: ABNT, 2013

De acordo com NBR 15575-5 (ABNT, 2013), um sistema de cobertura consiste em um conjunto de elementos/componentes, dispostos no topo de uma construção, com a função de garantir estanqueidade às águas pluviais e salubridade, protegendo os demais sistemas da edificação habitacional ou elementos e componentes da deterioração por agentes naturais. Para que se exerça tal função, a cobertura deve apresentar um nível de impermeabilização apropriado; sem isso os sistemas componentes da edificação poderão ser danificados devido à infiltração da água através da cobertura.

A análise realizada no presente artigo originou-se de Representação da Câmara Municipal de Teresina junto ao Tribunal de Contas do Estado do Piauí - TCE/PI, motivada por insatisfação daquela com os serviços provenientes da contratação de empresa para a realização de reparos nas coberturas de 06 (seis) Unidades de Saúde, ocorridos no ano de 2013. A partir disso a equipe técnica de engenharia do TCE/PI procedeu à apuração das irregularidades apontadas, exclusivamente no que se refere à contratação e execução da obra denunciada. As edificações hospitalares são discriminadas na Tabela 1 , a seguir.

Tabela 1 - Unidades hospitalares georreferenciadas (DATUM WGS84)

\begin{tabular}{c|l|l|l}
\hline ITEM & OBRA & Latitude (S) & Longitude(W) \\
\hline 01 & Hospital do Promorar & $5^{\circ} 08^{\prime} 54.8^{\prime \prime}$ & $42^{\circ} 46^{\prime} 55.3^{\prime \prime}$ \\
\hline 02 & Pronto Socorro do Dirceu Arcoverde & $5^{\circ} 06^{\prime} 31.4^{\prime \prime}$ & $42^{\circ} 45^{\prime} 25.0^{\prime \prime}$ \\
\hline 03 & Hospital Wall Ferraz - Cianca & $5^{\circ} 06^{\prime} 22.3^{\prime \prime}$ & $42^{\circ} 45^{\prime} 19.8^{\prime \prime}$ \\
\hline 04 & Hospital do Matadouro & $5^{\circ} 03^{\prime} 50.8^{\prime \prime}$ & $42^{\circ} 49^{\prime} 45.6^{\prime \prime}$ \\
\hline 05 & Hospital do Buenos Ayres & $5^{\circ} 02^{\prime} 30.4^{\prime \prime}$ & $42^{\circ} 48^{\prime} 55.6^{\prime \prime}$ \\
\hline 06 & Hospital do Satélite & $5^{\circ} 02^{\prime} 59.5^{\prime \prime}$ & $42^{\circ} 45^{\prime} 33.9^{\prime \prime}$ \\
\hline
\end{tabular}




\subsection{Objetivo Geral}

O trabalho teve como objetivo analisar manifestações patológicas em coberturas de edificações hospitalares da rede pública municipal de Teresina/PI.

\subsection{Objetivos Específicos}

Para tal, foi proposto:

- Determinar as manifestações patológicas presentes nas coberturas dos prédios estudados;

- Avaliar as prováveis causas para as manifestações encontradas;

- Propor possíveis soluções para os problemas identificados.

\section{METODOLOGIA}

Inicialmente, procurou-se conhecer as características gerais dos sistemas de cobertura das obras inspecionadas, por meio dos projetos fornecidos pelos órgãos responsáveis pela contratação e execução da obra. Informações acerca do projeto arquitetônico, como caimento e dimensões das águas dos telhados, foram extraídas e comparadas com a situação real das edificações. Além disso, realizou-se o levantamento das áreas para posteriores análises das coberturas.

Com o intuito de verificar as manifestações patológicas, foram realizadas inspeções visuais in loco, acompanhadas de técnicos de todos os entes envolvidos, objetivando determinar as características principais das manifestações e suas prováveis causas, bem como dirimir questionamentos a respeito das obras.

Os dados obtidos das inspeções compuseram um relatório fotográfico com informações a respeito do período de execução das obras, no intuito de avaliar se as manifestações patológicas se deram com um período condizente com a vida útil mínima dos elementos.

\section{RESULTADOS E DISCUSSÕES}

A seguir se encontram os resultados obtidos nas inspeções in loco realizadas nas Unidades Hospitalares relacionadas na Tabela 1. As manifestações patológicas se encontram agrupadas por tipologia, além disso são citados os hospitais onde foram constatadas as ocorrências, seguido dos respectivos registros fotográficos.

\subsection{Danos em rincões e divisores de água (cumeeiras e espigões)}

Os telhados apresentaram fissuras na argamassa de assentamento das cumeeiras e espigões e, mesmo com alguns retoques, verificou-se a deterioração dos elementos. Tal falha foi registrada no Hospital do Promorar, Figuras 2 e 3, e no Hospital Wall Ferraz - CIANCA, Figura 4. Também houve ocorrência no Pronto Socorro do Dirceu Arcoverde, conforme apresentado na Figura 5, caso em que se constatou a ausência das peças da cumeeira no telhado de fibrocimento, o que caracteriza uma ocorrência mais grave, uma vez que sem essas peças não há qualquer tipo de vedação no encontro das peças, causando grandes infiltrações ao longo de toda região da cumeeira.

A ocorrência dessas manifestações patológicas na cobertura ocasiona infiltrações e goteiras, causando suscetibilidade a danos em equipamentos indispensáveis à população e, consequentemente, risco à segurança dos pacientes e demais usuários das unidades hospitalares afetadas. Além disso, o excesso de umidade pode tornar os ambientes de armazenamento de medicamentos impróprios, causando ainda mais prejuízos a quem depende do serviço público de saúde.

Para mitigar os efeitos ocasionados pela deterioração do assentamento em argamassa das cumeeiras, pode-se utilizar de mantas asfálticas (como demonstrado na Figura 3), porém assegurando que a faixa protegida compreenda uma largura suficiente para garantir a estanqueidade necessária. Outra solução é a remoção de possíveis telhas danificadas, seguido da aplicação da argamassa nas regiões necessárias, com o posterior emprego a frio de uma manta líquida de base asfáltica nas interfaces entre as telhas, de forma a assegurar uma impermeabilização eficiente nessa região. Já nas telhas de fibrocimento, recomenda-se que as peças danificadas sejam trocadas, com a posterior fixação dos novos elementos tanto à estrutura existente quanto aos elementos que já se encontram no telhado, garantindo assim sua maior eficiência. 


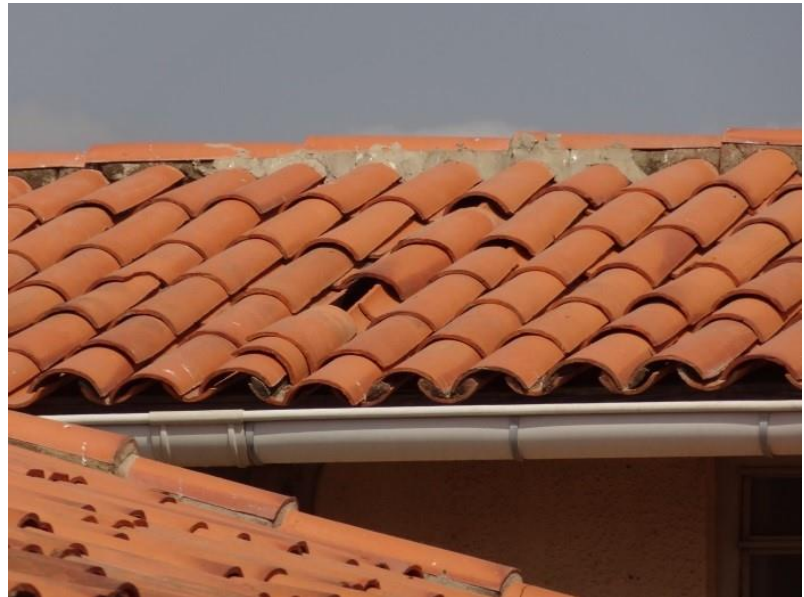

Figura 2: Falhas e retoques na cumeeira, mau posicionamento e ausência de telhas (Hospital do Promorar) Fonte: TCE/PI

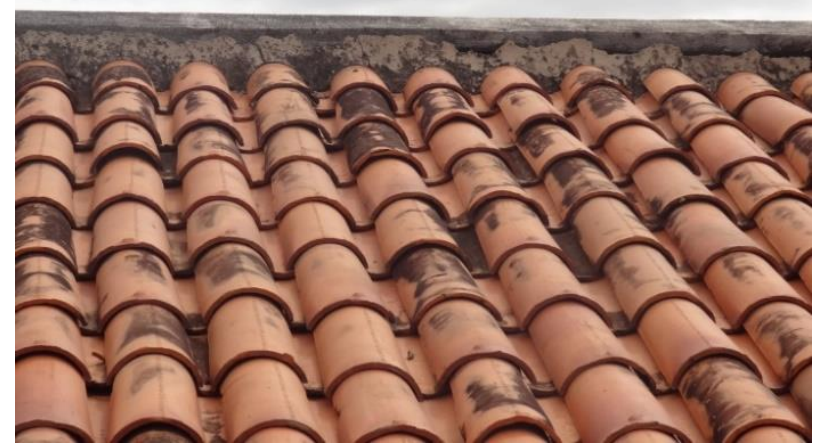

Figura 4: Fissuras e deterioração do emassamento da Cumeeira (Hospital Wall Ferraz - CIANCA) Fonte: TCE/PI

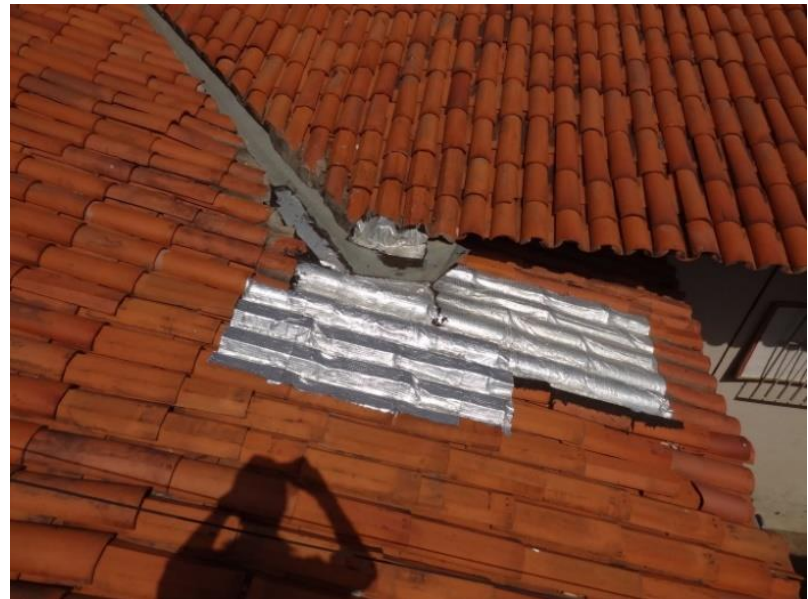

Figura 3: Danos no encontro entre as águas com reparo em manta asfáltica (Hospital do Promorar) Fonte: TCE/PI

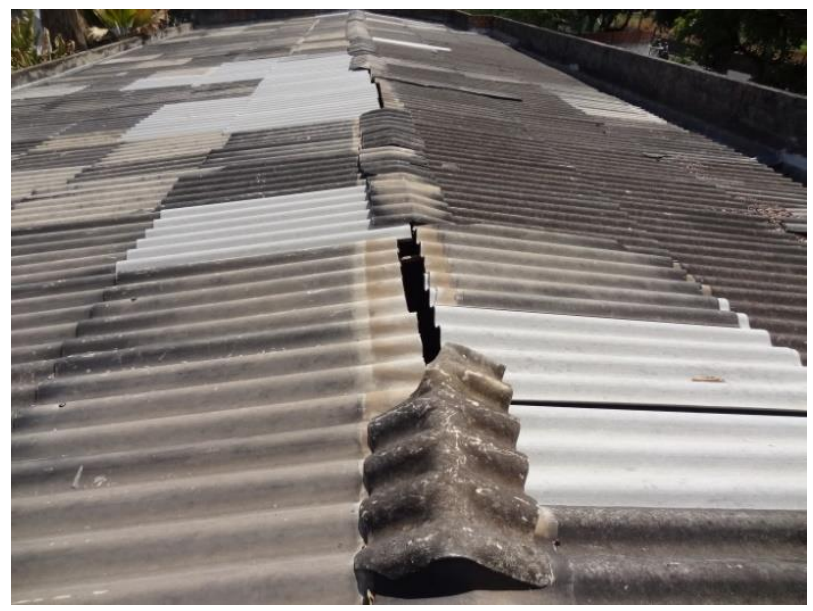

Figura 5: Ausência das peças de cumeeira em telhado de Fibrocimento (Pronto Socorro do Dirceu Arcoverde) Fonte: TCE/PI

\subsection{Ausência ou mau alinhamento do telhamento}

Foram observados, também, casos de telhamento cerâmico ausente em algumas regiões, conforme apresentado na Figura 2 (Hospital do Promorar) e Figura 6 (Hospital do Satélite). Tal manifestação ocasiona a livre entrada das águas pluviais nas zonas sem as telhas cerâmicas, ocasionando os danos às estruturas dos hospitais citados anteriormente.

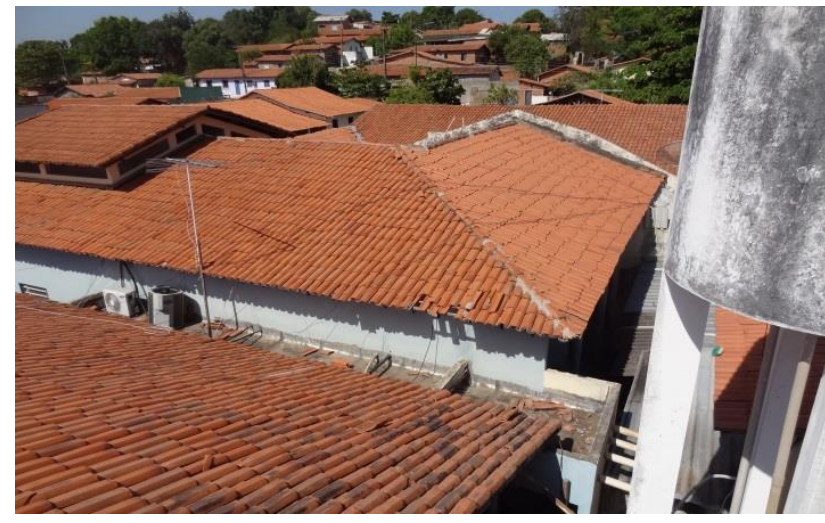

Figura 6: Ausência de telhas cerâmicas no beiral (Hospital do Satélite) Fonte: TCE/PI

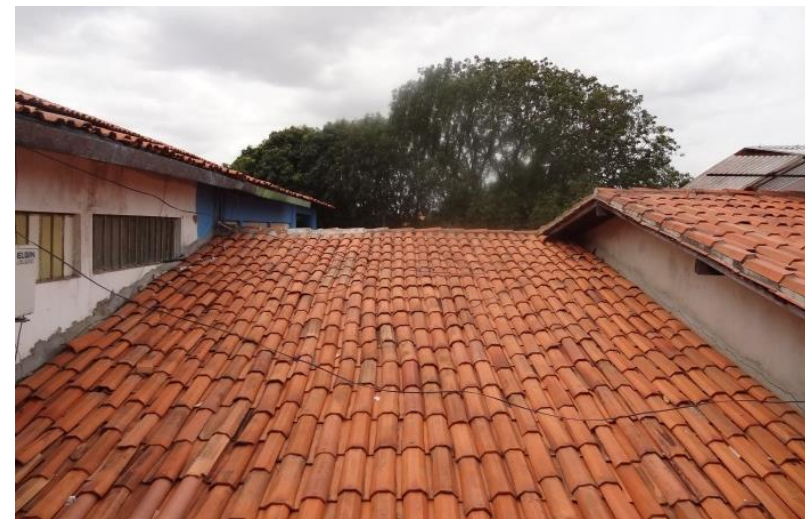

Figura 7: Falta de alinhamento entre as peças cerâmicas (Hospital do Buenos Ayres) Fonte: TCE/PI 


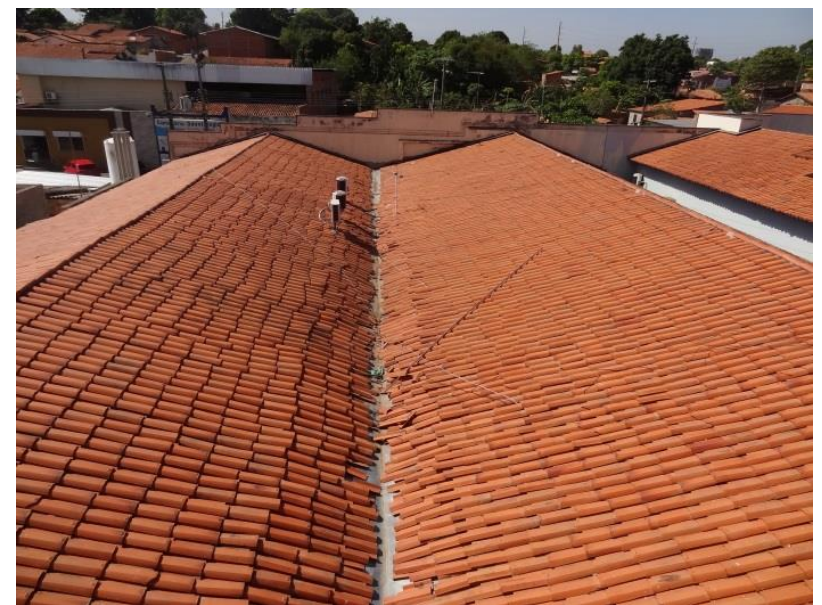

Figura 8: Não alinhamento das telhas na extremidade do telhado (Hospital do Satélite) Fonte: TCE/PI

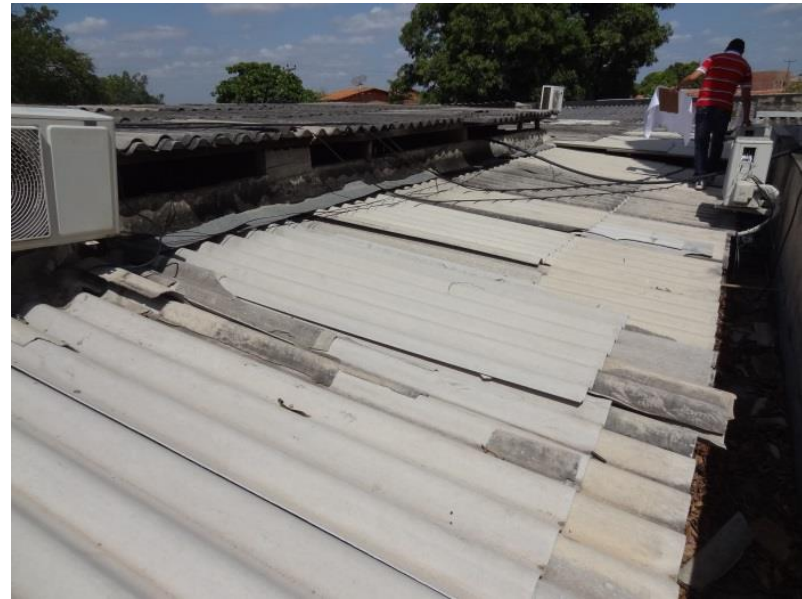

Figura 9: Telhas de várias dimensões no mesmo plano de telhado, desalinhadas nas extremidades (Pronto Socorro do Dirceu Arcoverde) Fonte: TCE/PI

Além disso, houve a ocorrência do mal alinhamento das peças constituintes do telhamento. Isso pode ser devido à má colocação das peças, ou ao escorregamento das telhas aliado à falta de ações corretivas. Constatou-se o mau alinhamento no Hospital do Buenos Ayres, conforme Figura 7; Hospital do Satélite, como apresentado na Figura 8 e também no Pronto Socorro do Dirceu Arcoverde, Figura 9.

Acredita que manifestações patológicas dessa natureza originam-se de falhas na trama de sustentação do telhado cerâmico. Dessa forma ao se realizar o retelhamento para a correção da cobertura, deve-se realizar uma revisão na estrutura de suporte, a fim de mitigar efeitos de possíveis empenamentos ou flechas excessivas. Nas telhas de fibrocimento, foi constatado o uso de telhas de diferentes tamanhos pela construtora; tal prática não é recomendada, pois essas diferenças podem ocasionar locais sem a devida cobertura. Assim, para se garantir uma cobertura eficiente, deve-se empregar materiais de dimensões uniformes com as devidas fixações.

\subsection{Ausência ou má aplicação dos elementos de fixação de telhas de fibrocimento}

As telhas de fibrocimento consistem em placas com ondulações. A título comparativo, não constituem elementos isolados como as telhas cerâmicas e são bem mais leves, dessa forma são suscetíveis à ação de sucção do vento. Portanto, se faz necessária a correta fixação dessas telhas à estrutura de suporte da cobertura, podendo essa fixação ser através de parafusos ou ganchos. A ausência desses elementos favorece o desprendimento das telhas, situação verificada no Pronto Socorro do Dirceu Arcoverde, conforme apresentado na Figura 10. Além disso, a colocação dos elementos em inconformidade com o recomendado para o material (por exemplo: distâncias insuficientes até a borda) pode causar a ruptura da telha, limitando sensivelmente a efetividade da ligação. Essa manifestação também foi observada no Pronto Socorro do Dirceu Arcoverde, de acordo com a Figura 11.

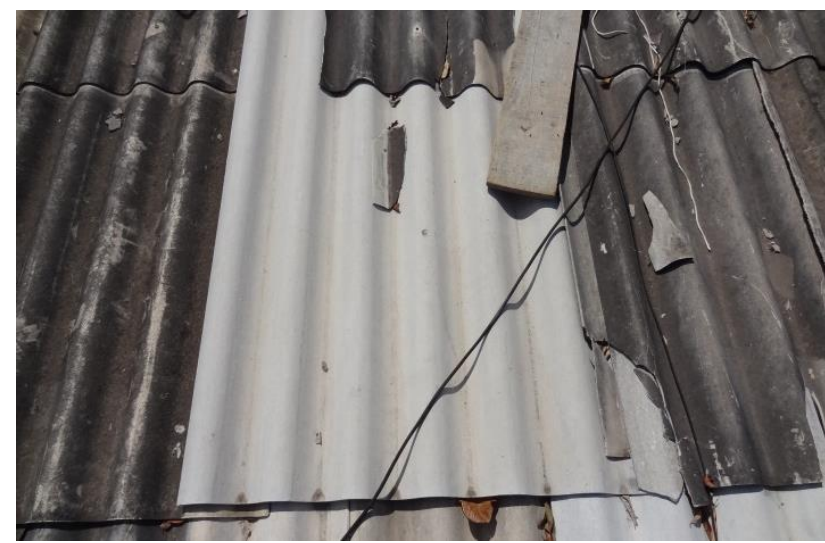

Figura 10: Telhas colocadas sem elementos de fixação (Pronto Socorro do Dirceu Arcoverde) Fonte: TCE/PI

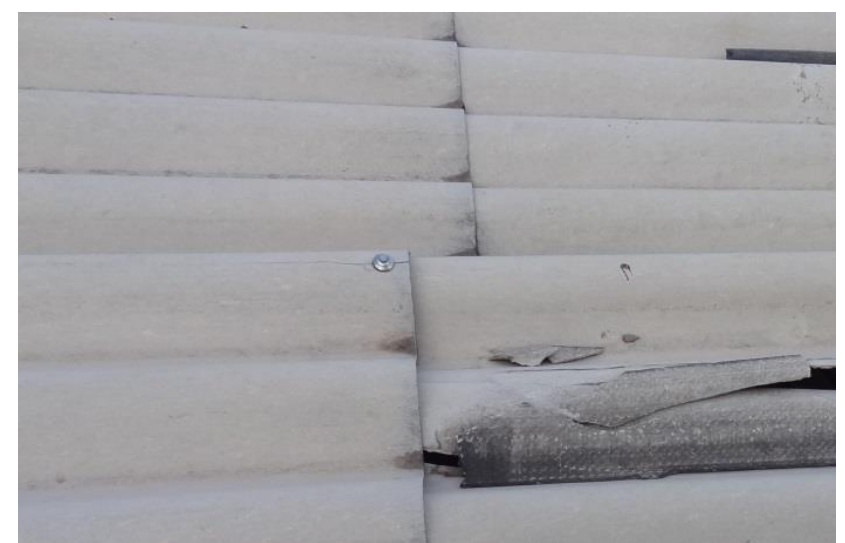

Figura 11: Parafuso colocado indevidamente, ocasionando trinca na telha (Pronto Socorro do Dirceu Arcoverde) Fonte: TCE/PI 
Para a devida fixação, recomenda-se a utilização dos parafusos e ganchos apropriados para o tal fim, respeitando as distâncias entre os pontos de fixação na estrutura, diâmetros dos furos e distâncias do furo até a borda da telha.

\subsection{Ausência ou inadequação de elementos de condução de águas pluviais}

Além de garantir a impermeabilização da área coberta da edificação, um sistema de cobertura apropriado deve englobar mecanismos de condução adequados das águas pluviais captadas pela superfície do telhado. Essas águas pluviais devem ser conduzidas até as sarjetas, onde terão uma destinação apropriada no sistema de drenagem. A situação das obras inspecionadas evidenciou o não atendimento a alguns desses requisitos: as calhas e demais condutores horizontais são insuficientes ou até inexistentes, além da falta de descidas para a água, de acordo com o encontrado no Hospital do Buenos Ayres e Hospital do Promorar (Figura 13 e Figura 14, respectivamente). Observou-se também a condução inapropriada no passeio público, conforme apresentado na Figura 12. Uma concepção cuidadosa do sistema de drenagem da edificação garante que os problemas ocasionados sejam solucionados.

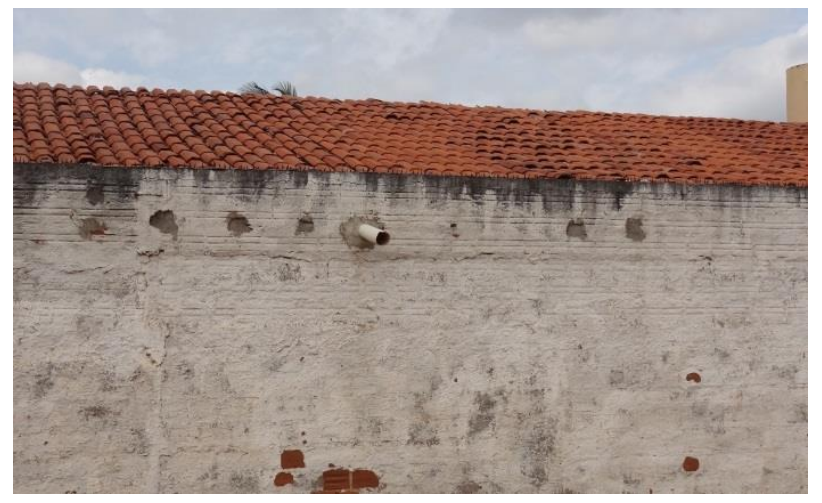

Figura 12: Condutor horizontal desaguando no passeio público (Hospital do Matadouro) Fonte: TCE/PI

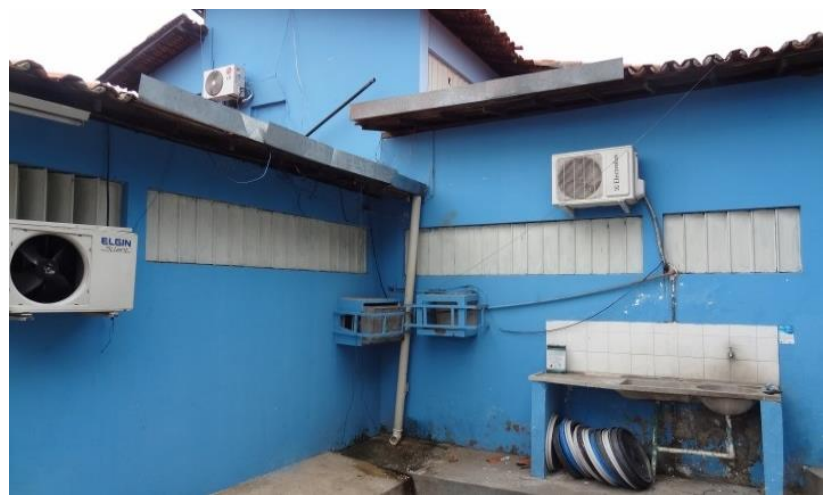

Figura 13: Calhas não acompanhando toda a extensão do telhado e ausência de condutores horizontais (Hospital do Buenos Ayres) Fonte: TCE/PI

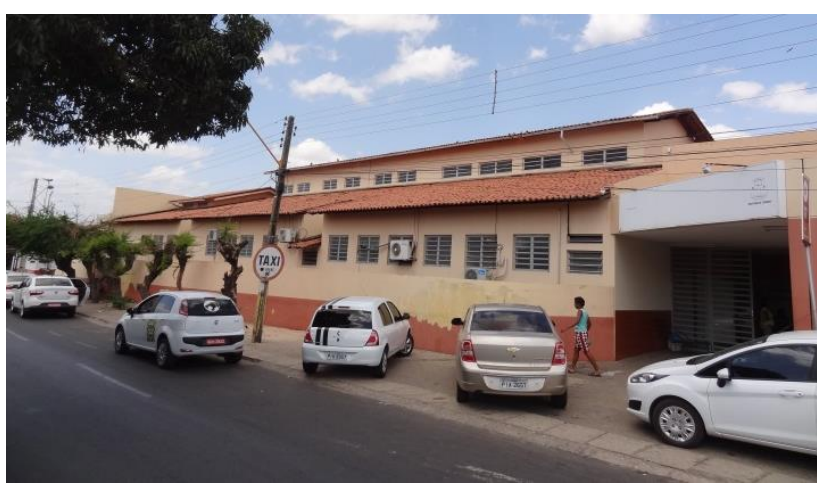

Figura 14: Plano de telhado inferior sem dispositivos condutores de águas pluviais (Hospital do Promorar) Fonte: TCE/PI

\subsection{Falta de acessibilidade para manutenção em regiões dos telhados}

Além da preocupação com anomalias construtivas oriundas das diversas fases da edificação, deve-se ter atenção especial às falhas geradas pela falta de manutenção nas edificações, pois essa desempenha um papel importante no desempenho do sistema como um todo. A Figura 8, por exemplo, demonstra o caso do Hospital do Satélite, onde o telhado cerâmico das águas centrais não fornece um acesso livre para a manutenção, refletindo no escorregamento das telhas sem as devidas medidas corretivas.

Conforme apresentado na Figura 15, o acesso à fachada frontal do Hospital do Buenos Ayres se torna difícil em condições usuais, por conta da elevada altura. Em ambos os casos tais situações torna a comprometer a troca de peças danificadas ou reparo de elementos, o que pode desencadear outras manifestações patológicas caso as iniciais não sejam sanadas oportunamente. 
Por ser uma falha originada no projeto das edificações, soluções como a substituição do sistema de cobertura por outros que demandem de menos manutenção, pode reduzir os custos. Porém, qualquer que seja a solução necessita do devido planejamento para que se englobe todos os elementos constituintes da cobertura.

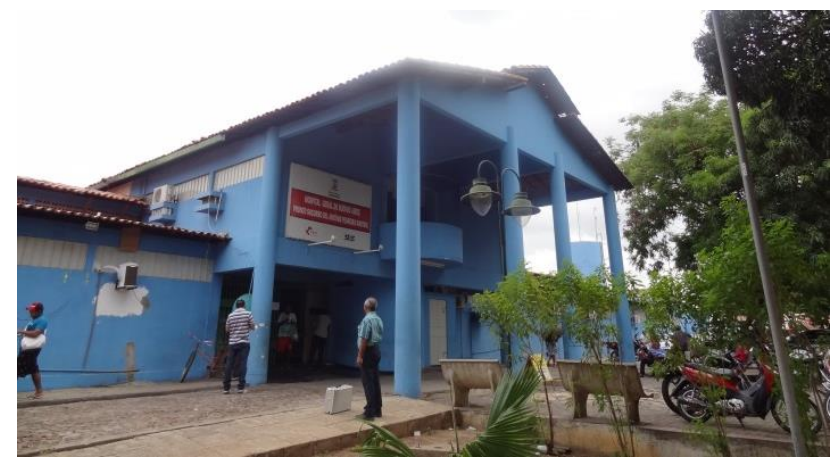

Figura 15: Cobertura de acesso complexo devido à altura (Hospital do Buenos Ayres) Fonte: TCE/PI

\section{CONCLUSÕES}

Nas edificações estudadas foram verificadas diversas manifestações patológicas oriundas de diferentes fases, desde a concepção do projeto (áreas de difícil manutenção poderiam ser melhor concebidas, ou serem utilizados outros sistemas de cobertura que necessitam de menos manutenção), execução (telhas mal fixadas, ou com um certo desalinhamento) e também de falhas nos serviços de reparo fornecidos pela empresa contratada (como a ausência das peças das cumeeiras nos telhados de fibrocimento). Dessa forma, tais situações evidenciam o envolvimento de diversas partes que culminam em diferentes manifestações.

Portanto, para se garantir níveis aceitáveis de desempenho, segurança e prolongamento da vida útil das edificações, é de suma importância a realização de trabalhos rotineiros que busquem a identificação das manifestações patológicas, suas causas e meios de prevenção e correção.

Outra benesse trazida pelas frequentes e corretas atividades de manutenção é subsídio aos profissionais da construção civil nas tomadas de decisão tanto em âmbito de planejamento quanto de execução, para que sejam adotadas medidas preventivas frente aos problemas que podem se originar em uma edificação mal planejada e carente de serviços de manutenção.

Por se tratarem de obras públicas de grande importância para a população, os impactos gerados por essas manifestações patológicas devem ser mitigados ao máximo, não só por conta da descontinuidade de um serviço essencial em casos extremos, mas por conta de que os reparos constantes e ineficientes configuram dispêndio do recurso público.

Sobre esse ponto, ressalta-se, por fim, a importância da atuação dos órgãos de controle, a exemplo do TCE/PI com seu corpo técnico de engenharia, a fim de garantir, além da boa e correta governança, o comprometimento das partes envolvidas em fornecer um serviço de qualidade à população, minimizando os custos extras que essas manifestações patológicas geram aos cofres públicos.

\section{REFERÊNCIAS}

ASSOCIAÇÃO BRASILEIRA DE NORMAS TÉCNICAS. NBR 15575-1: Edificações habitacionais - Desempenho, Parte 1: Requisitos Gerais. Rio de Janeiro, 2013.

ASSOCIAÇÃO BRASILEIRA DE NORMAS TÉCNICAS. NBR 15575-5: Edificações habitacionais - Desempenho, Parte 5: Requisitos para os sistemas de coberturas. Rio de Janeiro, 2013.

ASSOCIAÇÃO BRASILEIRA DE NORMAS TÉCNICAS. NBR 9575: Impermeabilização - Seleção e Projeto. Rio de Janeiro, 2010. 


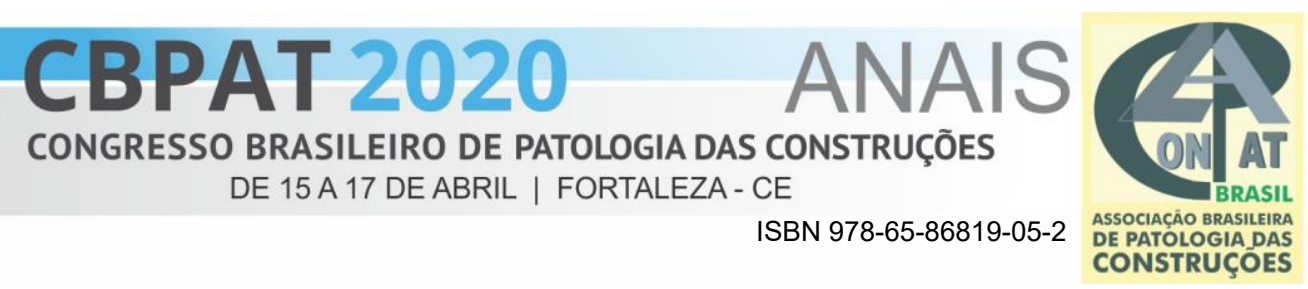

GOMIDE, T. L.; FAGUNDES NETO, J. C. P.; GULLO, M. A. Normas Técnicas para Engenharia Diagnóstica em Edificações. São Paulo. Pini, 2009.

SAldAnha, M. S. Inspeção Predial no Senado da República - Agora é Projeto de Lei. Semana Oficial da Engenharia e Agronomia, Ed. 69. 2012. Distrito Federal. Disponível em: <http://www.crears.org.br/site/documentos/69SOEA_Brasilia_DF_Inspecao_Predial_22_11_2012.pdf >. Acesso em: 11 nov. 2019. 